\title{
Renal Vasoconstriction Caused by Short-term Cholesterol Feeding Is Corrected by Thromboxane Antagonist or Probucol
}

\author{
Randy Kaplan, Hagop S. Aynedjian, Detlef Schlondorff, and Norman Bank \\ Renal Division, Department of Medicine, Montefiore Medical Center and the Albert Einstein College of Medicine, Bronx, New York 10467
}

\begin{abstract}
Recent studies indicate that short-term cholesterol feeding causes vascular hyperreactivity and/or increased tone in certain vascular beds. The present study in rats examined the effect of 3 wk of cholesterol-supplemented diet (CSD) on renal hemodynamics. We tested the hypothesis that LDL oxidized in vivo is causally related to increased renal vascular tone by adding the antioxidant drug probucol to the CSD (CSD + P). Micropuncture of surface nephrons in the CSD rats demonstrated that single nephron glomerular filtration rate (SNGFR) and single nephron afferent plasma flow $\left(Q_{A}\right)$ were markedly lower than in normal rats, whereas glomerular capillary pressure $\left(P_{G C}\right)$, afferent arteriolar resistance $\left(R_{A}\right)$, and single nephron filtration fraction (SNFF) were higher. In the CSD $+P$ animals, almost all of these hemodynamic abnormalities were absent. $\mathrm{TXB}_{2}$ and $\mathrm{PGE}_{2}$ were increased in proximal tubule fluid and urine in the CSD rats, but normal in the CSD $+P$ group. Infusion of a $\mathbf{T X A}_{2}$ receptor antagonist into the suprarenal aorta of CSD rats caused a rapid return to normal of RBF (renal blood flow), GFR (glomerular filtration rate), SNGFR, $Q_{A}, R_{A}, P_{G C}$, and $K_{f}$ (ultrafiltration coefficient). Our observations demonstrate that cholesterol feeding leads to renal vasoconstriction, which appears to be mediated largely by increased $T X A_{2}$ production. The fact that probucol prevented the hemodynamic abnormalities as well as the increased TX production is consistent with the hypothesis that LDL oxidized in vivo initiates events leading to $\mathbf{T X}$ mediated vasoconstriction. (J. Clin. Invest. 1990. 86:1707-1714.) Key words: renal hemodynamics • hyperlipidemia • micropuncture • prostaglandins $\bullet$ renal injury
\end{abstract}

\section{Introduction}

Hyperlipidemia and hypercholesterolemia are thought to contribute to the pathogenesis of the progression of renal disease in several animal models (1). In support of this hypothesis, lipid-lowering agents have been shown to reduce renal injury in hyperlipidemic animals (1). Furthermore, elevating cholesterol by diets enriched in cholesterol can produce renal injury in normal rats. Kasiske et al. (2) found increased glomerulosclerosis in normal rats fed a high cholesterol diet for five

This study was reported in part at the American Society of Nephrology 22nd annual meeting, 3-6 December, 1989, and published in abstract form by the Society $(183 A)$.

Address reprint requests to Dr. N. Bank, Dept. of Medicine, Montefiore Medical Center, 111 East 210 Street, Bronx, NY 10467.

Received for publication 28 November 1989 and in revised form 2 July 1990.

J. Clin. Invest.

(c) The American Society for Clinical Investigation, Inc.

$0021-9738 / 90 / 11 / 1707 / 08 \quad \$ 2.00$

Volume 86, November 1990, 1707-1714 months. The hypercholesterolemia was associated with increased intraglomerular pressure, indicating altered glomerular hemodynamics. In addition to the long-term histological effects of hypercholesterolemia, it has been found that shortterm elevation of serum cholesterol can cause vasoconstriction and/or increased reactivity to vasoactive agents in several vascular beds (3-9). For example, in rabbits fed a cholesterol-supplemented diet for $2 \mathrm{wk}$, coronary artery constriction led to a greater degree of myocardial damage than in control animals or in rabbits treated with lovastatin to lower serum cholesterol (3). The isolated coronary arteries failed to relax normally when exposed to acetylcholine (3). Golino et al. (4) found that only $3 \mathrm{~d}$ of a $2 \%$ cholesterol diet in rabbits caused a doubling of experimental myocardial infarct size, and Heistad et al. (6) demonstrated that hind limb arteries of hypercholesterolemic monkeys had an augmented constrictor response to norepinephrine. In vitro studies by Andrews et al. (8) and Kugiyama et al. (9) showed that human or rabbit LDL inhibited endothelium-dependent relaxation of aortic rings of rabbits, thus implicating LDL as a possible agent mediating vasoconstriction in hypercholesterolemia. In all of these studies, the observed effects on blood vessels were thought to be functional in nature, as the length of hypercholesterolemia was too brief to produce visible atheromatous changes.

This study was carried out to examine the effect of $3 \mathrm{wk}$ of a cholesterol-supplemented diet (CSD) ${ }^{1}$ on renal hemodynamics in rats. Because it has been clearly demonstrated that in vitro chemically modified (oxidized) LDL is toxic to cultured endothelial and mesangial cells (10-14), we tested the hypothesis that LDL oxidized in vivo is causally related to the vascular tone abnormalities. We fed the antioxidant drug, probucol, which prevents oxidation of LDL by endothelial cells in vitro (12-14). Finally, the effect of a $\mathrm{TXA}_{2}$ receptor antagonist, $S \mathrm{~K}$ and $\mathrm{F} 96148$, on renal hemodynamics was studied. We found that the cholesterol-supplemented diet caused renal vasoconstriction at pre- and presumably postglomerular sites. There was in addition an increase in both $\mathrm{PGE}_{2}$ and $\mathrm{TXB}_{2}$ in proximal tubular fluid and urine. These changes were almost completely prevented by adding probucol to the high cholesterol diet. Infusion of the $\mathrm{TXA}_{2}$ receptor antagonist into the aorta above the renal arteries of cholesterol-fed rats caused immediate reversal of all the renal hemodynamic abnormalities. Our observations are therefore consistent with the hypothesis that LDL oxidized in vivo initiates events leading

1. Abbreviations used in this paper: CSD, pellet diet supplemented with $4 \%$ cholesterol and $1 \%$ cholic acid; FFP, proximal tubule free-flow pressure; $K_{\mathrm{f}}$, ultrafiltration coefficient; MAP, mean arterial pressure; ND, regular rat pellet diet; $P$, probucol; $\Delta \mathrm{P}$, transcapillary hydraulic pressure; $P_{G C}$, glomerular capillary pressure; $Q_{A}$, single nephron afferent plasma flow; $R_{A}$, afferent arteriolar resistance; $R B F$, renal blood flow; RE, efferent arteriolar resistance; SNBF, single nephron blood flow; SNFF, single nephron filtration fraction. 
to vasoconstriction, and that this vasoconstriction is mediated in large part by $\mathrm{TXA}_{2}$.

\section{Methods}

Male Sprague-Dawley rats weighing $200-280 \mathrm{~g}$ were maintained in individual metabolic cages, and were fed a ration of $20 \mathrm{~g} / \mathrm{d}$ of either a regular rat pellet diet (ND) or a pellet diet supplemented with $4 \%$ cholesterol and $1 \%$ cholic acid (CSD) (Teklad Diets, Madison, WI) for 3 wk. The ND and CSD were of the exact same composition with regard to protein, carbohydrates, minerals, and vitamins, but all these constituents were $5 \%$ less/wt in the CSD diet because of the addition of cholesterol and cholic acid. All animals consumed the entire daily ration of $20 \mathrm{~g}$. They had free access to tap water. At the end of $3 \mathrm{wk}$, micropuncture and whole kidney clearance studies were carried out as described below. Six groups of animals were studied.

Group I: normal controls (ND). Six rats consumed the regular rat pellet diet, $20 \mathrm{~g} / \mathrm{d}$, for 2-3 wk. At the end of this time, whole kidney and single nephron hemodynamic measurements were made under general anesthesia, using methods described in detail in previous publications (15-17). The data from these animals have been recently published $(15,16)$. In six additional rats fed the ND, overnight urine collections were made in vials containing $0.3 \mu \mathrm{M}$ meclofenemate for analysis of $\mathrm{PGE}_{2}$ and $\mathrm{TXB}_{2}$. Urines were frozen at $-70^{\circ} \mathrm{C}$ until analyzed. Aortic blood was collected from these animals for measurement of liver chemistries and plasma lipid profile.

Group II: normal rats fed probucol $(N D+P)$. In six rats, probucol (kindly supplied by Merrell Dow Research Institute, Cincinnati, $\mathrm{OH}$ ) was added to the ND to provide $10 \mathrm{mg} / \mathrm{d}$ in $20 \mathrm{~g}$ of the diet. The probucol was dissolved in ethyl alcohol, and the solution was then applied to the food pellets and air dried. In these six animals, whole kidney GFR and renal blood flow (RBF) were measured, but micropuncture was not performed. RBF was measured by an ultrasonic flow probe (Transonic Systems, Inc., Ithaca, NY) placed around the left renal artery, and GFR for both kidneys was measured by $\left[{ }^{14} \mathrm{C}\right]$ inulin clearance via timed urine collections from the bladder.

Group III: cholesterol-supplemented diet (CSD). Six rats were fed $20 \mathrm{~g} / \mathrm{d}$ of the CSD for $3 \mathrm{wk}$. At the end of this time, whole kidney and single nephron hemodynamic measurements were made, as in the group I animals. In five additional rats fed the CSD for $3 \mathrm{wk}$, overnight urine collections were obtained in metabolic cages for $\mathrm{PGE}_{2}$ and $\mathrm{TXB}_{2}$ measurement, and aortic blood was collected for liver chemistries and plasma lipid analysis.

Group IV: cholesterol-supplemented diet + probucol $(C S D+P)$. Six rats were fed the same CSD as the group III rats, except that probucol was added to the pellets to provide $10 \mathrm{mg} / \mathrm{d}$. At the end of $3 \mathrm{wk}$, whole kidney and single nephron hemodynamic measurements were made by micropuncture methods. Six additional rats were fed the CSD + P diet for 3 wk, after which overnight urine was collected for $\mathrm{PGE}_{2}$ and $\mathrm{TXB}_{2}$ measurement. Aortic blood was collected from these animals for liver chemistries and plasma lipid analysis.

Group V: measurements of $P G E_{2}$ and $T X B_{2}$ in early proximal tubule fluid. Measurements of $\mathrm{PGE}_{2}$ and $\mathrm{TXB}_{2}$ in tubular fluid collected from early segments of the proximal convoluted tubule were carried out in four control rats, six CSD rats, and six CSD + P rats. Methods used to collect tubular fluid for prostaglandin determination have been described in detail (18). Collections of $\sim 75-150 \mathrm{nl}$ of tubular fluid were obtained in micropipettes that had been rinsed with $1.5 \mathrm{mg} / \mathrm{ml}$ bovine serum albumin in saline. The entire collected sample was discharged into polyethylene vials. The samples were frozen at $-70^{\circ} \mathrm{C}$ until analyzed. An enzyme immunoassay for $\mathrm{PGE}_{2}$ and $\mathrm{TXB}_{2}$ was used as described previously $(18,19)$. The antibodies for $\mathrm{PGE}_{2}$ and $\mathrm{TXB}_{2}$ were kindly provided by Dr. P. Pradelles, and their specificity has been reported in detail (19).

Group VI: infusion of thromboxane receptor antagonist, $S K$ and $F$ 96148. In four control ND rats, six CSD rats, and six CSD + P rats, the $\mathrm{TXA}_{2}$ receptor antagonist, S K and F 96148 (formerly BM 13.505; kindly supplied by Smith, Kline, and French Laboratories, Swedeland, PA) $(20,21)$ was infused into the abdominal aorta above the origin of the renal arteries after initial micropuncture measurements of glomerular hemodynamics had been obtained. The surgical preparation of these animals was the same as for the other groups except that PE 10 tubing was inserted in a femoral artery and threaded up the aorta until it could be seen through the wall of the exposed aorta to be above the renal arteries. The location of the catheter was confirmed in some experiments by bolus injection of a small volume of F D \& C green dye, which resulted in a flush of the left (micropuncture) kidney. In addition, an ultrasonic flow probe was placed around the left renal artery for continuous monitoring of RBF. After initial micropuncture and whole kidney hemodynamic measurements were made, S K and F 96148 was injected into the aortic catheter in an initial dose of 1 $\mathrm{mg} / \mathrm{kg}$, followed by a continuous infusion of $1 \mathrm{mg} / \mathrm{kg}$ per $\mathrm{h}(21) . \mathrm{RBF}$ to the left kidney was recorded continuously, and repeat micropuncture measurements of single nephron hemodynamics were made using fresh surface structures. In three additional rats fed the CSD for $3 \mathrm{wk}$, RBF was monitored by the ultrasonic flow probe and GFR was measured by $\left[{ }^{14} \mathrm{C}\right]$ inulin before and during intraaortic infusion of saralasin in a bolus dose of $10 \mu \mathrm{g} / \mathrm{kg}$ followed by a constant infusion of $10 \mu \mathrm{g} / \mathrm{kg}$ per min.

Micropuncture methods. The surgical preparation of the animals on the day of study and the micropuncture methods have been described previously in detail (15-17). The measurements carried out in the present study were: single nephron glomerular filtration rate (SNGFR), single nephron afferent plasma flow $\left(Q_{A}\right)$, single nephron blood flow $(\mathrm{SNBF})$, glomerular capillary pressure $\left(\mathrm{P}_{\mathrm{GC}}\right)$, proximal tubule free-flow pressure (FFP), transcapillary hydraulic pressure $(\Delta P)$, and single nephron filtration fraction (SNFF). The ultrafiltration coef-

Table I. Whole Animal Data

\begin{tabular}{|c|c|c|c|c|c|c|c|}
\hline \multirow[b]{2}{*}{ Group } & \multirow[b]{2}{*}{$n$} & \multicolumn{2}{|c|}{ Body weight } & \multirow[b]{2}{*}{ MAP } & \multirow[b]{2}{*}{ Hct } & \multirow[b]{2}{*}{ GFR } & \multirow[b]{2}{*}{ RBF } \\
\hline & & I & $\mathbf{F}$ & & & & \\
\hline & & & & $m m H g$ & $\%$ & $\mathrm{ml} / \mathrm{min}$ & $\mathrm{ml} / \mathrm{mm}$ \\
\hline ND & 6 & $265 \pm 9$ & $288 \pm 8$ & $126 \pm 1$ & $45.6 \pm 0.2$ & $2.21 \pm 0.16$ & $5.98 \pm 0.57$ \\
\hline $\mathrm{ND}+\mathrm{P}$ & 6 & $242 \pm 6$ & $271 \pm 4$ & $120 \pm 1^{*}$ & - & $2.11 \pm 0.06^{\ddagger}$ & $6.38 \pm 0.05^{\S}$ \\
\hline CSD & 6 & $214 \pm 7^{\|}$ & $246 \pm 11^{17}$ & $113 \pm 2^{* *}$ & $45.7 \pm 0.6$ & $1.19 \pm 0.05^{* *}$ & $4.53 \pm 0.29$ \\
\hline $\mathrm{CSD}+\mathrm{P}$ & 6 & $242 \pm 12$ & $283 \pm 8$ & $114 \pm 1^{* *}$ & $45.0 \pm 3$ & $2.17 \pm 0.14^{\ddagger}$ & $6.14 \pm 0.32$ \\
\hline
\end{tabular}

Data expressed as mean \pm standard error of mean. N, number of animals; I, initial; F, final. ND, normal diet; ND + P, normal diet + probucol; CSD, cholesterol-supplemented diet; CSD + P, CSD + probucol. ' $P<0.05$ vs. ND; " $P<0.01$ vs. ND; ${ }^{* *} P<0.001$ vs. ND; ${ }^{*} P<0.05$ vs. CSD; ${ }^{\S} P<0.01$ vs. CSD; ${ }^{\ddagger} P<0.001$ vs. CSD. GFR values are for two kidneys. RBF is for the left kidney only. 
Table II. Liver Chemistries and Serum Lipids

\begin{tabular}{lccccccccc}
\hline Group & Albumin & $\begin{array}{c}\text { Total } \\
\text { bilirubin }\end{array}$ & SGOT & SGPT & Total cholesterol & Triglyceride & $\begin{array}{c}\text { LDL } \\
\text { cholesterol }\end{array}$ & $\begin{array}{c}\text { VLDL } \\
\text { cholesterol }\end{array}$ & $\begin{array}{c}\text { HDL } \\
\text { cholesterol }\end{array}$ \\
\hline & \multicolumn{1}{c}{$g / d l$} & $m g / d l$ & IU/liter & $I U / l i t e r$ & $m g / d l$ & $m g / d l$ & $m g / d l$ & $m g / d l$ & $m g / d l$ \\
ND & $2.9 \pm 0.1(6)$ & $0.3 \pm 0.0(6)$ & $179 \pm 14(6)$ & $44 \pm 4(6)$ & $59 \pm 4(10)$ & $76 \pm 17(8)$ & $15 \pm 2(6)$ & $4 \pm 1(6)$ & $24 \pm 4(6)$ \\
CSD & $3.3 \pm 0.1^{*}(5)$ & $0.3 \pm 0.0(5)$ & $216 \pm 36(5)$ & $83 \pm 21(5)$ & $228 \pm 22^{*}(15)$ & $61 \pm 7(14)$ & $42 \pm 8(6)$ & $115 \pm 19(6)$ & $17 \pm 6(6)$ \\
CSD + P & $3.0 \pm 0.1(6)$ & $0.3 \pm 0.0(6)$ & $179 \pm 8(6)$ & $52 \pm 3(6)$ & $199 \pm 19^{*}(14)$ & $51 \pm 5(13)$ & $54 \pm 4(6)$ & $41 \pm 13(6)$ & $25 \pm 8(6)$
\end{tabular}

Numbers in parentheses are number of animals. In the case of LDL, VLDL, and HDL, samples from two animals had to be pooled, thereby reducing $n$ to 3 . Statistics were therefore not carried out for these determinations. ${ }^{*} P<0.05$ vs. ND.

ficient $\left(K_{f}\right)$ was derived from the mathematical model of Deen et al. (22). Afferent arteriolar resistance $\left(\mathbf{R}_{\mathbf{A}}\right)$ was calculated as previously described (17).

Analytic methods. Total cholesterol and triglyceride concentrations were measured using quantitative enzymatic assays (Sigma Chemical Co., St. Louis, MO) $(23,24)$. Serum lipids were separated into VLDL, LDL, and HDL fractions by previously described methods (25). It was necessary to pool serum from two animals in order to carry out each fractionation. Cholesterol in each fraction was measured by enzymatic assay (23). Serum protein was measured by the Lowry method. Liver chemistries were measured by the central laboratory autoanalyzer.

Statistical analyses. In each micropuncture experiment, all data obtained from an individual animal were averaged, and this single average represented that animal. Differences among group averages were analyzed by ANOVA and tested for significance by the Scheffe posthoc test. In the group VI experiments, in which pre- and post$\mathrm{TXA}_{2}$ antagonist infusion data were obtained, analysis was by Student's paired $t$ test.

\section{Results}

Whole animal data. In Table I are shown whole animal data obtained at the time of micropuncture study. As can be seen, although there were small differences in body weight among the groups at the start of the experiments, all groups gained weight during the $3 \mathrm{wk}$ of diet rationing. During renal function study under general anesthesia, mean arterial pressure (MAP) was significantly lower in the CSD and CSD + $P$ groups than in the ND animals, although the pressures in all groups were well within the normal range. GFR measured for both kidneys by urine collected from the bladder, was significantly lower in the CSD rats than in the ND group or in the CSD + P group. RBF measured by an ultrasonic flow probe on the left renal artery was numerically but not significantly lower in the CSD animals than in the ND animals, but it was significantly lower than in either the ND + P or the CSD + P rats. Addition of probucol to the normal diet did not have any significant effect on GFR or RBF (ND vs. ND + P). Bird et al. (26) previously reported that probucol administration to normal rats had no significant effect on serum creatinine. Blood Hct was comparable in the three groups in which it was measured.

Table II presents liver chemistries and cholesterol in various lipid fractions in additional rats fed the same diets. Serum albumin was slightly but significantly higher in the CSD group than in the ND animals, but there were no significant differences in total bilirubin, serum glutamic oxaloacetic transaminase (SGOT), or serum glutamic pyruvic transaminase (SGPT) among the three groups. Total cholesterol was signifi- cantly elevated in the CSD vs. ND animals. Probucol in a dose of $10 \mathrm{mg} / \mathrm{d}$ led to a small but insignificant decline in total cholesterol, but no apparent change in LDL cholesterol. The mean VLDL cholesterol was also increased in the CSD group, in agreement with observations by Arbeeny et al. (27). Probucol appeared to lower VLDL levels, but because of large variability and the fact that VLDL had to be determined in pooled blood reducing the $n$, statistical analysis was not carried out. HDL cholesterol was not affected by cholesterol feeding or probucol.

The SNGFR data, plasma flow, and $\mathrm{R}_{\mathrm{A}}$ are shown in Fig. 1. As can be seen, there was a $32 \%$ decrease in SNGFR in the CSD animals, as compared with the ND rats. Addition of probucol to the CSD completely prevented this fall in SNGFR, the mean value being equal to that in the ND rats. Plasma flow entering the glomerulus $\left(Q_{A}\right)$ was $43 \%$ lower in the CSD rats than in the ND animals. Probucol largely prevented this fall, $Q_{A}$ being $90 \pm 6 \mathrm{nl} / \mathrm{min}$, a value not significantly different from that in the ND rats. $R_{A}$ was increased in the CSD group, but addition of probucol to the CSD completely prevented the rise in $\mathbf{R}_{\mathbf{A}}$.
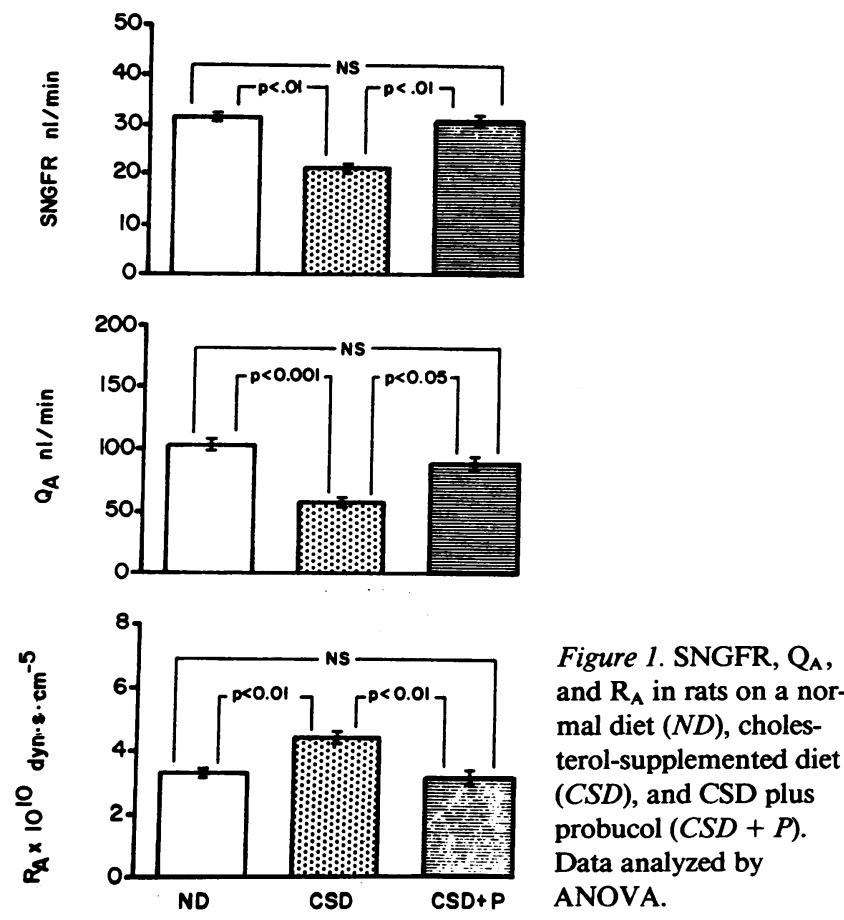
Table III. Micropuncture Results in Groups I-III

\begin{tabular}{lcccccccc}
\hline Group & $n$ & $\mathrm{SNBF}$ & $\mathrm{P}$ & $\Delta \mathrm{P}$ & $\mathrm{SNFF}$ & $K_{\mathrm{f}}$ & $\pi \mathrm{A}$ & $\pi \mathrm{E}$ \\
\hline & & $n l / m i n$ & $m m H g$ & $m m H g$ & & $n l / m i n$ per $m m H g$ & $m m H g$ & $m m H g$ \\
ND & 6 & $189 \pm 6$ & $48.7 \pm 0.4$ & $37.4 \pm 0.4$ & $0.30 \pm 0.01$ & $2.01 \pm 0.07$ & $16.0 \pm 0.4$ & $28.0 \pm 0.6$ \\
$\mathrm{CSD}$ & 6 & $107 \pm 6^{*}$ & $53.2 \pm 1.2^{\ddagger}$ & $40.9 \pm 1.2$ & $0.37 \pm 0.01^{*}$ & $1.64 \pm 1.01$ & $17.2 \pm 1.0$ & $35.5 \pm 2.5^{\ddagger}$ \\
$\mathrm{CSD}+\mathrm{P}$ & 6 & $163 \pm 11^{\S}$ & $50.2 \pm 1.0$ & $38.4 \pm 0.8$ & $0.35 \pm 0.01^{\ddagger}$ & $2.40 \pm 0.19^{\S}$ & $17.1 \pm 0.9$ & $33.0 \pm 1.3$ \\
& & & & & & & &
\end{tabular}

${ }^{*} P<0.001$ vs. ND; ${ }^{\ddagger} P<0.05$ vs. ND; ${ }^{\S} P<0.05$ vs. CSD.

Additional single nephron hemodynamic data are shown in Table III. SNBF was $43 \%$ lower in the CSD group than in the ND animals, and this fall was prevented by probucol. $P_{G C}$ was significantly higher in the CSD animals than in the ND, in spite of the lower MAP (Table I) and the increase in $R_{A}$. In addition, SNFF was increased in the CSD rats. Taken together, these observations strongly imply that efferent arteriolar resistance (RE) was also increased, although RE was not directly evaluated. The mean value of the ultrafiltration coefficient, $K_{f}$, in the CSD rats was not significantly lower than in the ND group $(P=0.06)$, but it was significantly lower than in the $\mathrm{CSD}+\mathrm{P}$ animals. Addition of probucol to the CSD resulted in prevention of all the hemodynamic abnormalities with the exception of SNFF, which remained significantly elevated.

$P G E_{2}$ and $T X B_{2}$ in proximal fluid and urine. Concentrations of $\mathrm{PGE}_{2}$ in early proximal tubule fluid reflect its intraglomerular generation (18). We therefore examined early proximal tubule micropuncture samples for $\mathrm{PGE}_{2}$ and $\mathrm{TXB}_{2}$. The quantity of $\mathrm{PGE}_{2}$ and $\mathrm{TXB}_{2}$ excreted in tubular fluid during a 10-min period is shown in Fig. 2. The data obtained in each animal were averaged, and the average was used to calculate group means and differences among the groups. As can be seen, $\mathrm{PGE}_{2}$ was significantly higher in the $\operatorname{CSD}(n, 6)$ than in the ND group $(n, 4)(0.236 \pm 0.01$ vs. $0.158 \pm 0.01 \mathrm{pg} / 10$ $\min )(P<0.05)$. $\mathrm{TXB}_{2}$ rose disproportionately to $\mathrm{PGE}_{2}$ in the CSD group (0.553 \pm .14 vs. $0.120 \pm .03)$. Addition of probucol to the $\operatorname{CSD}(n, 6)$ completely prevented the rise in both $\mathrm{PGE}_{2}$ $(0.17 \pm .02)$ and $\mathrm{TXB}_{2}(0.174 \pm .09)$ in early proximal tubular fluid. These changes in prostaglandins were also observed in the urine, as shown in Table IV. Both $\mathrm{PGE}_{2}$ and $\mathrm{TXB}_{2}$ were markedly increased in the urine of CSD vs. the ND group. Addition of probucol to the cholesterol diet resulted in a blunting of the rise in urinary $\mathrm{PGE}_{2}$ and prevention of the increase in $\mathrm{TXB}_{2}$ seen in the CSD animals.

Infusion of $T X A_{2}$ receptor antagonist or saralasin. The effects of infusion of the $\mathrm{TXA}_{2}$ receptor antagonist, $\mathrm{S} \mathrm{K}$ and $\mathrm{F}$ 96148 , into the aorta above the renal arteries are shown in Fig.

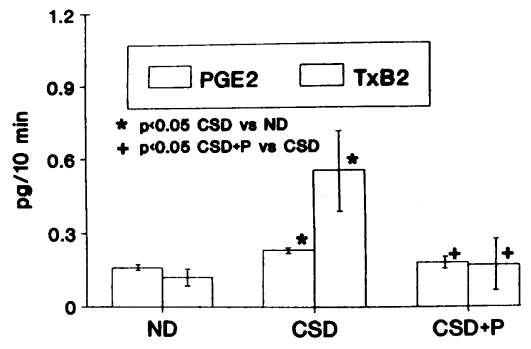

Figure 2. $\mathrm{PGE}_{2}$ and $\mathrm{TXB}_{2}$ in fluid collected from early proximal tubule segments. Data expressed as picograms excreted in $10 \mathrm{~min}$.
3 and Tables V and VI. In Fig. 3 SNGFR is shown before and during antagonist infusion in CSD and CSD + $P$ rats prepared by the same methods as the preceding groups. As can be seen, SNGFR was markedly decreased in the CSD animals during the control period, but rose strikingly during the antagonist infusion $(23.9 \pm 0.8$ vs. $32.6 \pm 2.2)(P<0.01)$. In the CSD $+P$ rats, there was no significant change in SNGFR with the antagonist infusion $(30.2 \pm 1.6$ vs. $30.6 \pm 2.1) . Q_{A}$ data for the same animals are also shown in Fig. 3. As in the case of SNGFR, $Q_{A}$ was significantly reduced in the CSD animals, but rose strikingly upon infusion of the $\mathrm{TXA}_{2}$ antagonist ( $67 \pm 2$ vs. $99 \pm 8$ ) $(P<0.01)$. In contrast, in the CSD $+P$ rats there was no significant change in $Q_{A}$ with infusion of the $T X A_{2}$ antagonist $(91 \pm 6$ vs. $91 \pm 7)$. $R_{A}$, expressed as $10^{10} \mathrm{dyn} \cdot \mathrm{s} \cdot \mathrm{cm}^{-5}$, was significantly elevated in the CSD rats, and fell with infusion of the TXA $_{2}$ antagonist $(4.29 \pm 0.13$ vs. $2.94 \pm 0.24)(P<0.001)$. No effect on $R_{A}$ was found in the CSD $+P$ animals $(3.16 \pm 0.2$ vs. $2.96 \pm 0.16$ ). Additional single nephron data are shown in Table V. In the CSD animals, $\mathrm{TXA}_{2}$ antagonist infusion resulted in significant changes in $\mathrm{SNBF}, \mathrm{P}_{\mathrm{GC}}, \Delta \mathrm{P}, \mathrm{SNFF}$, and $K_{\mathrm{f}}$, whereas in the CSD + $P$ rats there were no significant effects of the antagonist on any of these measurements. Whole kidney GFR and RBF for these experiments and for an additional group of ND rats are shown in Table VI. RBF of the left kidney was measured continuously by an ultrasonic flow probe on the renal artery. As can be seen, infusion of S K and F 96148 resulted in small but significant decreases in MAP in the CSD and CSD + P groups. GFR and RBF rose much more in the CSD than in the CSD + $\mathrm{P}$ animals. The rise in RBF occurred within 2-4 min after infusion of the $\mathrm{TXA}_{2}$ antagonist was started. There were no significant effects of S K and F 96148 on MAP or GFR in the ND rats, but RBF rose slightly. In a group of CSD animals infused with saralasin, there was no effect on GFR, and only a small rise in RBF. Thus, the reduced GFR and RBF in the CSD group responded acutely to a $T X A_{2}$ antagonist, but not to an angiotensin II receptor antagonist.

Table IV. Urinary $P G E_{2}$ and $T X B_{2}$

\begin{tabular}{lccc}
\hline Group & & $\mathrm{PGE}_{2}$ & $\mathrm{TXB}_{2}$ \\
\hline & & $p g / h$ & $p g / h$ \\
ND & 5 & $859 \pm 86$ & $130 \pm 19$ \\
CSD & 6 & $2,645 \pm 275^{*}$ & $481 \pm 50^{*}$ \\
CSD + P & 6 & $1,596 \pm 176^{\ddagger}$ & $131 \pm 22^{\ddagger}$
\end{tabular}

${ }^{*} P<0.01$ vs. ND; ${ }^{\ddagger} P<0.01$ vs. $\mathrm{CSD}$. 

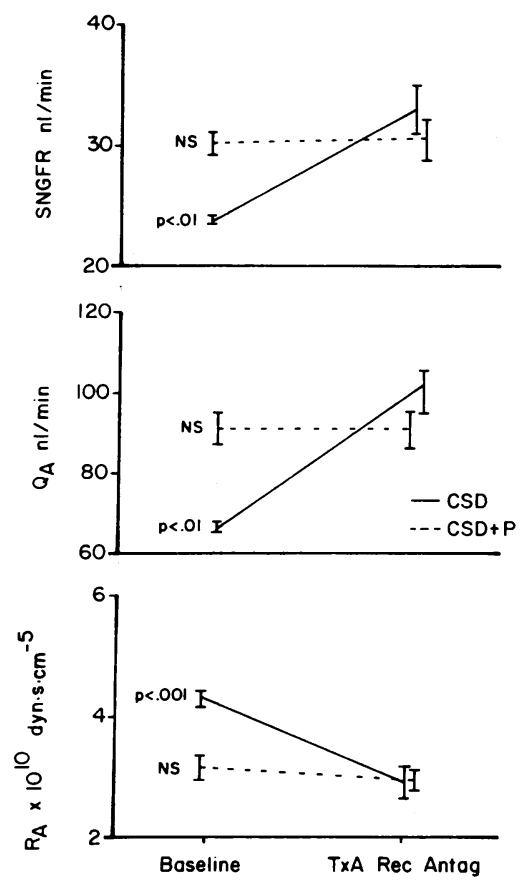

Figure 3. Effect of aortic infusion of $\mathrm{TXA}_{2}$ receptor antagonist on SNGFR, $Q_{A}$, and $R_{A}$ in $C S D$ and CSD $+P$ rats. $P$ values compare data before and during receptor antagonist infusion by paired $t$ test.

\section{Discussion}

The results of these experiments demonstrate that short-term dietary cholesterol supplementation in rats results in hypercholesterolemia and marked vasoconstriction of renal blood vessels. The vasoconstriction was localized by micropuncture measurements to the afferent arteriole and most likely to the efferent arteriole as well, since $P_{G C}$ and SNFF increased significantly in spite of the reduction in SNBF. Whole kidney blood flow, measured by an ultrasonic flow probe, was also markedly lower in the CSD rats than in the ND + P or the CSD + P animals. GFR was reduced by $36 \%$, as was SNGFR, in spite of a rise in $P_{G C}$ and $\triangle P$. Thus, the fall in GFR can be attributed to the reduction in $\mathrm{Q}_{\mathrm{A}}$, and probably in part to a fall in $K_{\mathrm{f}}$. These remarkable changes in renal vascular tone measured in vivo are presumably analogous to the increases in vascular contractility or failure of relaxation in response to various vasoactive drugs that have previously been demonstrated in isolated coronary blood vessels $(3-5,28)$, aorta (8), and hind limb arteries (6) consequent to hypercholesterolemia. In most of these previous studies, as well as in our own, the length of time of the experimental hypercholesterolemia was too short for gross pathologic lesions to develop in the blood vessels and therefore

the abnormalities are presumably functional in nature. Since the experimental diet had $1 \%$ cholic acid as well as $4 \%$ cholesterol, it has to be considered that some of the hemodynamic changes might be due to absorbed circulating cholate rather than hypercholesterolemia. This seems unlikely, however, since intravenous infusion of bile acids and bile salts in rats (29) or dogs (30) has been shown to have no effect on creatinine clearance, inulin clearance, or RBF.

Recently Kasiske et al. (2) reported increased intraglomerular pressures and efferent resistances in rats fed a cholesterolrich diet for $8 \mathrm{wk}$, findings in agreement with our own. However, in contrast to our results, these authors found no changes in RPF (renal plasma flow), GFR, or SNGFR. The reason for this difference is unclear, but may be due to the different durations of the diet ( $3 \mathrm{wk}$ vs. $8 \mathrm{wk}$ ) or to the amount of fluid replacement given during micropuncture studies. In general, both their study and ours demonstrate significant renal vasoconstriction induced by cholesterol feeding.

Several studies in recent years have shown that during incubation with cultured endothelial cells, LDL undergoes extensive physical and chemical modification which depends on an initial peroxidation of fatty acids in the LDL particles (14, $31-34)$. The chain of reactions, which occurs only upon contact of LDL with the cells, is totally prevented in vitro by the antioxidants butylated hydroxytoluene, probucol, and vitamin E $(12-14,34)$. The oxidized LDL has been found to be cytotoxic to endothelial cells (10-14), and it has been suggested that LDL inactivates endothelium-derived relaxing factor $(8$, 9). More recently, oxidized LDL, but not unmodified LDL, has been found to be toxic to glomerular mesangial cells (35). Because of these in vitro observations, we examined the hypothesis that LDL oxidized in vivo might be responsible for the renal vasoconstriction observed with cholesterol feeding. To do so, we fed rats the same CSD diet to which had been added $10 \mathrm{mg} / \mathrm{d}$ of the antioxidant drug probucol. As shown in Table II, total cholesterol and LDL cholesterol were much higher in the CSD rats than in the ND controls, as was VLDL cholesterol. Probucol feeding to CSD rats appeared to partially prevent the rise in total and VLDL cholesterol, but the concentrations remained 3-10 times above those in the ND rats. Moreover, LDL cholesterol was unaffected by probucol, and it remained 3.6 times higher than in the ND rats.

In spite of the elevation of total and LDL cholesterol in the CSD + P animals, these rats exhibited none of the renal hemodynamic abnormalities found in the CSD group. Whole kidney GFR, SNGFR, $Q_{A}, R_{A}$, and $P_{G C}$ were all indistinguishable from values in the ND rats. Thus, our observations are consistent with, though do not provide direct proof for, the hypoth-

Table V. Acute Effects of TXA Receptor Antagonist ${ }^{*}$ on Surface Nephron Hemodynamics

\begin{tabular}{|c|c|c|c|c|c|c|c|c|c|c|c|c|}
\hline \multirow{2}{*}{$\begin{array}{c}\text { Group } \\
(n)\end{array}$} & \multicolumn{2}{|c|}{ SNBF } & \multicolumn{2}{|c|}{$P_{G C}$} & \multicolumn{2}{|c|}{$\Delta \mathbf{P}$} & \multicolumn{2}{|c|}{ SNFF } & \multicolumn{2}{|c|}{$K_{\mathrm{f}}$} & \multicolumn{2}{|c|}{$\pi \mathrm{a}$} \\
\hline & 1 & 2 & 1 & 2 & 1 & 2 & 1 & 2 & 1 & 2 & 1 & 2 \\
\hline & \multicolumn{2}{|c|}{$\mathrm{nl} / \mathrm{min}$} & \multicolumn{2}{|c|}{$m m H g$} & \multicolumn{2}{|c|}{$m m H g$} & & & \multicolumn{2}{|c|}{$\mathrm{ml} / \mathrm{min}$ per $\mathrm{mmHg}$} & \multicolumn{2}{|c|}{$m m H g$} \\
\hline $\operatorname{CSD}(6)$ & $121 \pm 3$ & $178 \pm 14^{\ddagger}$ & $50.9 \pm 1.4$ & $49.3 \pm 1.1^{\ddagger}$ & $38.8 \pm 1.2$ & $37.3 \pm 1.1^{\ddagger}$ & $0.36 \pm 0.0$ & $0.33 \pm 0.0^{\ddagger}$ & $1.70 \pm 0.23$ & $2.49 \pm 0.50^{\ddagger}$ & $15.9 \pm 1.3$ & $15.9 \pm 1.3$ \\
\hline $\mathrm{CSD}+\mathrm{P}(6)$ & $165 \pm 11$ & $163 \pm 11$ & $51.6 \pm 0.8$ & $51.6 \pm 0.9$ & $39.9 \pm 0.8$ & $39.8 \pm 1.0$ & $0.33 \pm 0.0$ & $0.34 \pm 0.0$ & $2.45 \pm 0.24$ & $2.84 \pm 0.35$ & $18.8 \pm 0.8$ & $18.8 \pm 0.8$ \\
\hline
\end{tabular}

1, period 1, before $\mathrm{TXA}_{2}$ receptor antagonist; 2 , period 2, after $\mathrm{TXA}_{2}$ receptor antagonist. ${ }^{*} \mathrm{~S} \mathrm{~K}$ and $\mathrm{F} 96148 . \quad{ }^{\ddagger} P<0.05$ paired $t$ test. 
Table VI. Acute Effects of TXA, Antagonist or Saralasin on Renal Function*

\begin{tabular}{|c|c|c|c|c|c|c|c|c|c|}
\hline \multirow[b]{2}{*}{ Group A } & \multirow[b]{2}{*}{ Drug } & \multicolumn{2}{|c|}{ MAP } & \multicolumn{2}{|c|}{ GFR } & \multirow[b]{2}{*}{$\Delta$ GFR } & \multicolumn{2}{|c|}{ RBF } & \multirow[b]{2}{*}{$\triangle \mathrm{RBF}$} \\
\hline & & 1 & 2 & 1 & 2 & & 1 & 2 & \\
\hline & & \multicolumn{2}{|c|}{$m m H g$} & \multicolumn{2}{|c|}{$\mathrm{ml} / \mathrm{min}$} & $\mathrm{ml} / \mathrm{min}$ & \multicolumn{2}{|c|}{$\mathrm{ml} / \mathrm{min}$} & $\mathrm{ml} / \mathrm{min}$ \\
\hline ND (4) & SK + F 96148 & $122 \pm 2$ & $121 \pm 1$ & $1.18 \pm 0.05$ & $1.19 \pm 0.05$ & 0.01 & $5.98 \pm 0.57$ & $6.19 \pm 0.56^{\ddagger}$ & 0.21 \\
\hline $\operatorname{CSD}(6)$ & SK + F 96148 & $116 \pm 1$ & $113 \pm 2^{\ddagger}$ & $0.76 \pm 0.06$ & $1.03 \pm 0.09^{\ddagger}$ & 0.27 & $4.53 \pm 0.29$ & $5.65 \pm 0.35^{\ddagger}$ & 1.12 \\
\hline $\mathrm{CSD}+\mathrm{P}(6)$ & SK + F 96148 & $116 \pm 1$ & $111 \pm 1^{\ddagger}$ & $0.98 \pm 0.07$ & $1.01 \pm 0.07^{\ddagger}$ & 0.03 & $6.14 \pm 0.32$ & $6.34 \pm 0.33$ & 0.20 \\
\hline $\operatorname{CSD}(3)$ & Saralasin & $113 \pm 3$ & $110 \pm 3$ & $0.64 \pm 0.02$ & $0.67 \pm 0.01$ & 0.03 & $5.12 \pm 0.15$ & $5.28 \pm 0.13^{\ddagger}$ & 0.16 \\
\hline
\end{tabular}

GFR data for left kidney. ${ }^{*}$ RBF to left kidney measured by ultrasonic flow probe. ${ }^{\ddagger} P<0.05$ by paired $t$ test, comparing period 1 with period 2.

esis that the increased renal vascular tone in the CSD animals was a result of in vivo oxidation of LDL and VLDL. The modest lowering of VLDL cholesterol in the probucol-treated animals might have played an additional role.

The mechanism by which cholesterol feeding induced renal vasoconstriction was studied further by examining arachidonic acid metabolic products in tubular fluid collected from early proximal convolutions and in urine. It had previously been shown in in vitro studies that oxidized LDL increases $\mathrm{PGE}_{2}$ and $\mathrm{TXB}_{2}$ synthesis by certain cell types (36). Furthermore, type II hypercholesterolemia (LDL elevation) in man (37), and experimental hypercholesterolemia in rabbits $(38,39)$ are associated with increased platelet $\mathrm{TXB}_{2}$ production and platelet aggregability. Direct addition of LDL to normal platelets also stimulates thromboxane synthesis (40). In this study, $\mathrm{PGE}_{2}$ and $\mathrm{TXB}_{2}$ were found to be significantly increased in both proximal tubular fluid and urine of the CSD animals, an effect largely or completely prevented by probucol feeding. In a previous study, we showed that $\mathrm{PGE}_{2}$ in proximal tubular fluid derives predominantly from glomerular synthesis (18). The source of the $\mathrm{TXB}_{2}$ in the proximal tubular fluid can not be determined exactly. TXA 2 might derive from circulating cells and platelets, as well as from glomerular cells (41-43). It is difficult to reliably determine serum levels of $\mathrm{TXA}_{2}$, as blood collection activates platelets, thereby generating large amounts of $\mathrm{TXA}_{2}$. Therefore, we could not evaluate how much $\mathrm{TXA}_{2}$ was filtered from the plasma versus that which was produced within the glomerulus itself. In any case, the $\mathrm{TXB}_{2}$ levels measured in early proximal tubular fluid should be representative of local levels present in the glomerulus. The fact that urinary $\mathrm{PGE}_{2}$ and $\mathrm{TXB}_{2}$ levels were also markedly increased in the CSD rats (Table IV), argues in favor of enhanced renal cell eicosanoid synthesis. Measurements of nonmetabolized urinary $\mathrm{PGE}_{2}$ and $\mathrm{TXB}_{2}$, which we performed, are thought to reflect only intrarenal synthesis and not filtered prostanoids (42). The fact that the elevated $\mathrm{PGE}_{2}$ and $\mathrm{TXB}_{2}$ excretion was prevented by probucol is consistent with the hypothesis that in vivo oxidized LDL mediated the increase in arachidonic acid metabolites.

To examine the role of the increased thromboxane formation in the renal vasoconstriction observed in the CSD group, we infused the thromboxane receptor antagonist, S K and F 96148 , into the aorta immediately above the renal arteries. As shown in Fig. 3 and Tables V and VI, the TXA $\mathrm{T}_{2}$ antagonist had striking effects in the CSD animals, returning most hemody- namic abnormalities to or toward normal. The rise in $\mathrm{RBF}$ occurred within 2-4 min after start of the antagonist infusion. In sharp contrast, there was either no effect or a much smaller effect of the $\mathrm{TXA}_{2}$ antagonist in the CSD + P animals. In ND rats, infusion of the antagonist had no effect on GFR and only a trivial effect on RBF (Table VI), in agreement with observations by Wilkes et al. (44). Thus, in normal animals endogenous thromboxane appears to play little or no role in establishing renal vascular tone. However, exogenous administration of $\mathrm{TXA}_{2}$ agonists in normal rats causes a marked increase in renal vascular resistance and a fall in RBF and GFR (44-46). It is reasonable to conclude therefore that excessive production of endogenous $\mathrm{TXA}_{2}$ caused the renal vasoconstriction observed in the CSD animals. To examine whether another vasoconstrictor, AII, was playing a role, we infused the AII receptor antagonist saralasin into the suprarenal aorta of CSD rats. As shown in Table VI, there was little or no effect on GFR, RBF, or MAP. These observations suggest that the renal vasoconstriction caused by short-term cholesterol feeding was mediated in large part or exclusively by excess endogenous production of $\mathrm{TXA}_{2}$.

The potential clinical implications of these observations are not clear, but merit further studies. Whether or not hyperlipidemia in man causes functional vasoconstriction of the kidney and other vascular beds is not known. What role, if any, functional vasoconstriction and consequent elevation of $P_{G C}$ may play in the pathogenesis of renal diseases accompanied by hyperlipidemia $(1,47)$ is also unknown. The mediation of vasoconstriction by thromboxane in the rat is of considerable interest, as both platelets and thromboxane may play an important role in atherogenesis in general $(38,39,48)$ and in a number of glomerular diseases (49).

\section{Acknowledgments}

These studies were supported by U. S. Public Health Service grant 5 RO1 DK32469, American Heart Association grant-in-aid 87113, and Juvenile Diabetes Foundation grant 188366. Dr. Kaplan is the recipient of a research fellowship from the New York/New Jersey affiliate of the National Kidney Foundation.

\section{References}

1. Keane, W. F., B. L. Kasiske, and M. P. O'Donnell. 1988. Lipids and progressive glomerulosclerosis. Am. J. Nephrol. 8:261-271. 
2. Kasiske, B. L., M. P. O'Donnell, P. G. Schmitz, Y. Kim, and W. F. Keane. 1990. Renal injury of diet-induced hypercholesterolemia in rats. Kidney Int. 37:880-891.

3. Osborne, J. A., P. H. Lento, M. R. Siegfried, G. L. Stahl, B. Fusman, and A. M. Lefer. 1989. Cardiovascular effects of acute hypercholesterolemia in rabbits. J. Clin. Invest. 83:465-473.

4. Golino, P., P. R. Maroko, and T. E. Carew. 1987. The effect of acute hypercholesterolemia on myocardial infarct size and the no-reflow phenomenon during coronary occlusion-reperfusion. Circulation. 75:292-298.

5. Yokoyama, M., H. Akita, T. Mizutani, H. Fukuzaki, and Y. Watanabe. 1983. Hyperreactivity of coronary arterial smooth muscles in response to ergonovine from rabbits with hereditary hyperlipidemia. Circ. Res. 53:63-71.

6. Heistad, D. D., M. L. Armstrong, M. L. Marcus, D. J. Piegors, and A. L. Mark. 1984. Augmented responses to vasoconstrictor stimuli in hypercholesterolemic and atherosclerotic monkeys. Circ. Res. 54:711-718.

7. Shimokawa, H., H. Tomoike, S. Nabeyama, H. Yamamoto, H. Araki, and M. Nakamura. 1983. Coronary artery spasm induced in atherosclerotic miniature swine. Science (Wash. DC). 221:560-562.

8. Andrews, H. E., K. R. Bruckdorfer, R. C. Dunn, and M. Jacobs. 1987. Low-density lipoproteins inhibit endothelium-dependent relaxation in rabbit aorta. Nature (Lond.). 327:237-239.

9. Kugiyama, K., S. Kerns, J. D. Morrisett, M. Bucay, R. Roberts, and P. D. Henry. 1989. Oxidized LDL impairs endothelium-dependent vasorelaxation. Clin. Res. 37:841a. (Abstr.)

10. Henriksen, T., S. A. Evensen, and B. Carlander. 1979. Injury to human endothelial cells in culture induced by low density lipoprotein. Scan. J. Clin. Lab. Invest. 39:361-368.

11. Hessler, J. R., A. L. Robertson, Jr., and G. M. Chisholm. 1979. LDL-induced cytotoxicity and its inhibition by HDL in human vascular and smooth muscle and endothelial cells in culture. Atherosclerosis. 32:213-229.

12. Parthasarathy, S., S. G. Young, J. L. Witztum, R. C. Pittman, and D. Steinberg. 1986. Probucol inhibits oxidative modification of low density lipoprotein. J. Clin. Invest. 77:641-644.

13. Chisolm, G. M., III, and D. W. Morel. 1988. Lipoprotein oxidation and cytotoxicity: effect of probucol on streptozotocin-treated rats. Am. J. Cardiol. 62:20B-26B.

14. Steinberg, D., S. Parthasarathy, T. E. Carew, J. C. Khoo, and J. L. Witztum. 1989. Beyond cholesterol. Modifications of low-density lipoprotein that increase its atherogenicity. N. Engl. J. Med. 320:915924.

15. Bank, N., M. A. G. Lahorra, H. S. Aynedjian, and B. M Wilkes. 1988. Sodium restriction corrects hyperfiltration of diabetes. Am. J. Physiol. 254(Renal Fluid Electrolyte Physiol. 23):F668-F676.

16. Bank, N., M. Coco, and H. S. Aynedjian. 1989. Galactose feeding causes glomerular hyperperfusion: prevention by aldose reductase inhibition. Am. J. Physiol. 256(Renal Fluid Electrolyte Physiol. 25):F994-F999.

17. Bank, N., P. Mower, H. S. Aynedjian, B. M. Wilkes, and S. Silverman. 1989. Sorbinil prevents glomerular hyperperfusion in diabetic rats. Am. J. Physiol. 256(Renal Fluid Electrolyte Physiol. 25):F1000-F1006.

18. Schlondorff, D., H. S. Aynedjian, J. A. Satriano, and N. Bank. 1987. In vivo demonstration of glomerular $\mathrm{PGE}_{2}$ responses to physiological manipulations and experimental agents. Am. J. Physiol. 252(Renal Fluid Electrolyte Physiol. 21):F717-F723.

19. Pradelles, P., J. Grassi, and J. Maclouf. 1985. Enzyme immunoassays of eicosanoids using acetylcholine esterase as label: an alternative to radioimmunoassay. Anal. Chem. 57:1170-1173.

20. Bitterman, H., A. Yanagisawa, and A. M. Lefer. 1986. Beneficial actions of thromboxane receptor antagonism in hemorrhagic shock. Circ. Shock. 20:1-11.

21. Smith, E. F., III, and J. McDonald. 1988. Protective effects of the thromboxane receptor antagonists BM 13.177 and BM 13.505 against $U$ 46619-induced sudden death in rats. Pharmacology (Basel). 36:340-347.

22. Deen, W. M., C. R. Robertson, and B. M. Brenner. 1972. A model of glomerular ultrafiltration in the rat. Am. J. Physiol. 223:1178-1183.

23. Allain, C. A., L. S. Poon, C. S. G. Chan, W. Richmond, and P. C. Fu. 1974. Enzymatic determination of total serum cholesterol. Clin. Chem. 20:470-475.

24. Bucolo, G., and H. David. 1973. Quantitative determination of serum triglycerides by the use of enzymes. Clin. Chem. 19:476-482.

25. Wasserman, J., A. Santiago, V. Rifici, H. Holthofer, L. Scharschmidt, M. Epstein, and D. Schlondorff. 1989. Interactions of low density lipoprotein with rat mesangial cells. Kidney Int. 35:11681174.

26. Bird, J. E., K. Milhoan, C. B. Wilson, S. G. Young, C. A. Mundy, S. Parthasarathy, and R. C. Blantz. 1988. Ischemic acute renal failure and antioxidant therapy in the rat. J. Clin. Invest. 81:16301638.

27. Arbeeny, C. M., D. Edelstein, S. R. Freedman, and H. A. Eder. 1980. Serum lipoproteins of diabetic rats fed a high cholesterol diet. Diabetes. 29:774-777.

28. Verbeuren, T. J., F. H. Jordaens, L. L. Zoonekeyn, C. E. Van Hove, M.-C. Coene, and A. G. Herman. 1986. Effect of hypercholesterolemia on vascular reactivity in the rabbit. I. Endothelium-dependent and endothelium-independent contractions and relaxations in isolated arteries of control and hypercholesterolemic rabbits. Circ. Res. 58:552-564.

29. Aoyagi, T., and L. M. Lowenstein. 1968. The effect of bile acids and renal ischemia on renal function. J. Lab. Clin. Med. 71:686-692.

30. Finestone, H., C. Fechner, and M. Levy. 1984. Effects of bile and bile salt infusions on renal function in dogs. Can. J. Physiol. Pharm. 62:762-768.

31. Henriksen, T., E. M. Mahoney, and D. Steinberg. 1981. Enhanced macrophage degradation of low density lipoproteins previously incubated with cultured endothelial cells: recognition by the receptors for acetylated low density lipoproteins. Proc. Natl. Acad. Sci. USA. 78:6499-6503.

32. Parthasarathy, S., U. P. Steinbrecher, J. Barnett, J. L. Witztum, and D. Steinberg. 1985. The essential role of phospholipase $A_{2}$ activity in endothelial cell-induced modification of low density lipoprotein. Proc. Natl. Acad. Sci. USA. 82:3000-3004.

33. Steinbrecher, U. P., S. Parthasarathy, D. S. Leake, J. L. Witztum, and D. Steinberg. 1984. Modification of low density lipoprotein by endothelial cells involves lipid peroxidation and degradation of low density lipoprotein phospholipids. Proc. Natl. Acad. Sci. USA. 81:3883-3887.

34. van Hinsbergh, V. W. M., M. Scheffer, L. Havekes, and H. J. M. Kempen. 1986. Role of endothelial cells and their products in the modification of low-density lipoproteins. Biochim. Biophys. Acta. 878:49-64.

35. Coritsidis, G., V. Rifici, and D. Schlondorff. 1989. The effects of oxidized lipoproteins on cultured mesangial cells (MC). The American Society of Nephrology Abstracts. 314. (Abstr.)

36. Kita, T., Y. Nagano, M. Yokode, K. Ishii, N. Kume, S. Narumiya, and C. Kawai. 1988. Prevention of atherosclerotic progression in Watanabe rabbits by probucol. Am. J. Cardiol. 62:13B-19B.

37. Carvalho, A. C. A., R. W. Colman, and R. S. Lees. 1974. Platelet function in hyperlipoproteinemia. N. Engl. J. Med. 290:434438.

38. Zmuda, A., A. Dembinska-Kiec, A. Chytkowski, and R. J. Gryglewski. 1977. Experimental atherosclerosis in rabbits: platelet aggregation, thromboxane $A_{2}$ generation and anti-aggregatory potency of prostacyclin. Prostaglandins. 14:1035-1053.

39. Gryglewski, R. J., A. Dembinska-Kiec, A. Zmuda, and T. Gryglewska. 1978. Prostacyclin and thromboxane $A_{2}$ biosynthesis ca- 
pacities of heart, arteries and platelets at various stages of experimental atherosclerosis in rabbits. Atherosclerosis. 31:385-394.

40. Beitz, J., M. Panse, and W. Forster. 1983. Low density lipoprotein (LDL) from male volunteers stimulated the thromboxane formation by human platelets. Prostaglandins Leukotrienes. Med. 10:443448.

41. Scharschmidt, L. A., E. Lianos, and M. J. Dunn. 1983. Arachidonate metabolites and the control of glomerular function. Fed. Proc. 42:3058-3063.

42. Schlondorff, D., and R. Ardaillou. 1986. Prostaglandins and other arachidonic acid metabolites in the kidney. Kidney Int. 29:108119.

43. Petrulis, A. S., M. Aikawa, and M. J. Dunn. 1981. Prostaglandin and thromboxane synthesis by rat glomerular epithelial cells. Kidney Int. 20:469-474.

44. Wilkes, B. M., J. Solomon, M. Maita, and P. F. Mento. 1989. Characterization of glomerular thromboxane receptor sites in the rat.
Am. J. Physiol. 256(Renal Fluid Electrolyte Physiol. 25):F1111F1116.

45. Baylis, C. 1987. Effects of administered thromboxanes on the intact, normal rat kidney. Renal Physiol. 10:110-121.

46. Cirino, M., H. Morton, C. MacDonald, J. Hadden, and A. W. Ford-Hutchinson. 1990. Thromboxane $A_{2}$ and prostaglandin endoperoxide analogue effects on porcine renal blood flow. Am. J. Physiol. 258(Renal Fluid Electrolyte Physiol. 27):F109-F114.

47. Diamond, J. R., and M. J. Karnovsky. 1987. Exacerbation of chronic aminonucleoside nephrosis by dietary cholesterol supplementation. Kidney Int. 32:671-677.

48. Watanabe, J., H. J. Wohltmann, R. L. Klein, J. A. Colwell, and M. F. Lopes-Virella. 1988. Enhancement of platelet aggregation by low-density lipoproteins from IDDM patients. Diabetes. 37:16521657.

49. Lianos, E. A. 1989. Eicosanoids and the modulation of glomerular immune injury. Kidney Int. 35:985-992. 